\title{
Pengaruh Kreativitas, Proaktif dan Otonomi Terhadap Kinerja Usaha Makanan Dan Minuman
}

\author{
Cindi Cemosa dan Lydiawati Soelaiman \\ Program Studi Manajemen Fakultas Ekonomi \\ Universitas Tarumanagara \\ Email: Cindi.khang@gmail.com
}

\begin{abstract}
Food and beverage industry sector have considerable economic growth potential as seen from its contribution to the gross domestic product (GDP) growth of the non-oil and gas industry and increased investment. This study aims to determine whether creativity, proactive, and autonomy have an influence to the performance of food and beverage businesses in West Jakarta. The sampling technique used was judgmental sampling distributed to 41 food and beverage business owners in West Jakarta. The results of this study indicate that there is an influence of creativity, proactive, and autonomy to business performance.
\end{abstract}

Keywords: creativity, proactive, autonomy, business performance

\begin{abstract}
Abstrak: Sektor industri makanan dan minuman memiliki potensi pertumbuhan ekonomi cukup besar terlihat dari kontribusinya terhadap pertumbuhan produk domestik bruto (PDB) industri non-migas serta peningkatan realisasi investasi. Penelitian ini bertujuan untuk mengetahui apakah kreativitas, proaktif, dan otonomi memiliki hubungan dengan kinerja usaha makanan dan minuman di Jakarta Barat. Teknik pengambilan sample yang digunakan adalah judgemental sampling yang disebarkan ke 41 orang pemilik usaha makanan dan minuman di Jakarta Barat. Hasil dari penelitian ini menunjukkan bahwa adanya pengaruh kreativitas, proaktif, dan otonomi terhadap kinerja usaha.
\end{abstract}

Kata kunci: kreativitas, proaktif, otonomi, kinerja usaha

\section{LATAR BELAKANG}

Wirausaha memiliki peran penting dalam perekonomian dan pembangunan nasional indonesia. Wirausaha berperan sebagai penyedia lapangan kerja baru yang dapat mengurangi tingkat pengangguran. Menurut Sulistyastuti (2004) "pengembangan Usaha Kecil Menengah memiliki peranan yang besar dalam pengembangan industri manufaktur" sehingga dengan bertambahnya jumlah unit usaha kecil menengah akan memunculkan industri-industri kecil yang baru serta memunculkan pengusaha-pengusaha yang baru dan akan berdampak pada pertumbuhan Produk Domestik Regional Bruto.

Menurut Menteri Perindustrian Airlangga Hartarto (2019) sektor industri makanan dan minuman memiliki potensi pertumbuhan ekonomi yang cukup besar . Pada triwulan I tahun 2019, pertumbuhan produk domestik bruto (PDB) industri makanan dan minuman mencapai 6,77\%. Selain itu sektor makanan dan minuman berkontribusi sebesar 35,58\% terhadap PDB Industri Non Migas dan sebesar 6,35\% terhadap PDB Nasional. Sektor makanan dan minuman juga menarik investasi sebesar US\$.383 juta dan Rp.8,9 triliun hingga triwulan I Tahun 2019 (https://www.pikiran-rakyat.com). Maka dapat disimpulkan bahwa sektor industri makanan dan minuman merupakan bidang usaha yang diminati oleh wirausaha.

Dalam membangun suatu usaha, seorang calon wirausaha harus mengetahui terlebih dahulu faktor-faktor yang dapat mempengaruhi keberhasilan atau kinerja usahanya. Menurut 
Brahmasari (2004) kinerja adalah pencapaian atas tujuan organisasi yang dapat berbentuk output kuantitatif maupun kualitatif, kreatifitas, fleksibilitas, atau hal-hal lain yang diinginkan oleh organisasi. Dalam mencapai kinerja usaha yang di inginkan terdapat beberapa faktor yang mempengaruhinya misalnya kreativitas, proaktif dan otonomi.

Menurut Munandar (2012) kreativitas adalah kemampuan untuk melihat berbagai kemungkinan penyelesaian suatu masalah, dalam bentuk pemikiran seperti pengetahuan dan ingatan. Menurut Eddy Poernomo (2006) Kreativitas dapat meningkatkan kinerja, untuk itu dalam proses mencapai profitabilitas yang dinginkan perlu ada kreativitas dari setiap anggota organisasi, karena dengan adanya kreativitas dalam membuat sesuatu baik barang atau jasa dan gagasan akan mempermudah dalam bekerja.

Untuk meningkatkan kinerja usaha seorang wirausaha juga perlu memiliki kemampuan proaktif. Menurut J Michael Crant (2000) Sikap Proaktif membutuhkan beberapa faktor pendukung seperti Identifikasi peluang, antisipasi terhadap perubahan permintaan dimasa depan, menyusun rencana strategis guna tercapainya tujuan, dan tindak lanjut dari eksekusi bisnis. Menurut I Made Sukaryawan (2013) dengan menciptakan peluang baru, selalu berinovasi, dan proaktif dalam melihat peluang pasar yang ada dapat mendorong peningkatan kinerja.

Otonomi wirausaha merupakan salah satu faktor yang menyebabkan banyak orang tertarik dalam membuka usaha sendiri. Menurut Lumpkin \& Dess (2005) Otonomi adalah keleluasaan atau kebebasan individu dalam berfikir dan bertindak kreatif dalam mengatasi berbagai persoalan atau dalam mengoptimalkan peluang baru yang menarik di pasar. Menurut Reskino (2016; dalam Harwita dan Ade Irma Suryani,2018) Otonomi merupakan tingkat kebebasan, independensi, dan kebijaksanaan yang dimiliki seseorang dalam merencanakan suatu pekerjaan dan menentukan cara apa yang digunakan untuk melaksanakanya agar mencapai hasil yang diinginkan.

\section{KAJIAN TEORI}

Kreativitas. Menurut Wright (2005: 105) Kreativitas didefinisikan sebagai“Creativity consists only of originality, and unlimited freedom. Creativity is more than that. Creativity also applies the rules of the game. How to think creatively, how to think generally, how to think creatively that can be understood, accepted, and appreciated by general thinking. If not, the results of thinking it will look strange and not creative." Artinya, Kreativitas hanya terdiri dari orisinalitas, dan kebebasan tanpa batas. Kreativitas lebih dari itu. Kreativitas juga menerapkan aturan. Bagaimana cara berpikir kreatif, bagaimana cara berpikir secara umum, bagaimana berpikir secara kreatif yang dapat dipahami, diterima, dan dihargai oleh pemikiran umum. Jika tidak, hasil berpikir tersebut akan terlihat aneh dan tidak kreatif.

Menurut Suharyadi (2007: 97) Mendeskripsikan bahwa kreativitas adalah kemampuan untuk mengembangkan ide-ide baru dan cara-cara baru dalam pemecahan masalah dan menemukan peluang (thinking new thing).

Menurut Supriadi (1994; dalam Yuliati 2007: 176) Mendeskripsikan bahwa kreativitas adalah kemampuan seseoraang untuk melahirkan sesuatu yang baru, baik berupa gagasan maupun karya nyata yang relatif berbeda dengan apa yang telah ada sebelumnya.

Proakif. Menurut Johannessen, J.-A., Olaisen, J. \& Olsen,B. (1999: 4) Proaktif adalah "Proactive is the ability to create opportunities or the ability to overcome or encourage and overcome the opportunities (or threats) of their compilation by themselves ". Artinya, Proaktif adalah kemampuan untuk menciptakan peluang atau kemampuan untuk mengenali atau mengantisipasi dan bertindak atas peluang (atau ancaman) ketika mereka muncul dengan sendirinya. 
Menurut Lumpkin and Dess, (2001: 431) Proaktif adalah"Perspective looking for existing opportunities, forward-looking by introducing new products or services before competitors and anticipating future demands to create change and shape the environment". Artinya, perspektif mencari peluang yang ada, berwawasan ke depan dengan memperkenalkan produk atau layanan baru terlebih dahulu sebelum pesaing dan melakukan antisipasi permintaan masa depan untuk menciptakan perubahan dan membentuk lingkungan".

Menurut Aloulou, W., \& Fayolle, A. (2005: 28) Proaktif adalah "proactivity is a response to opportunities that refers to "how companies are related to market opportunities by taking initiative and leading in the marketplace". Artinya, proaktif adalah respons terhadap peluang yang merujuk pada bagaimana perusahaan terkait dengan peluang pasar dengan mengambil inisiatif dan memimpin dalam pasar ".

Otonomi. Menurut Lambing, Peggy A \& Kuehl, Charles R. (2007: 23-24) Otonomi adalah "autonomy is the need for freedom and independence to make a decision. A feeling that expresses its own satisfaction being a leader is very satisfying for entrepreneurs". Artinya, otonomi adalah kebutuhan akan kebebasan dan kemerdekaan untuk membuat suatu keputusan. Sebuah perasaan yang menyatakan sebuah kepuasan tersendiri menjadi seorang pemimpin yang sangat memuaskan bagi wirausaha.

Menurut Gautam (2016; dalam Syed Zulfiqar Ali Shah dan Maqsood Ahmad, 2019: 558) Otonomi adalah "Autonomy is defined as the actions and independent decisions taken by individuals or teams to achieve organizational goals, and bring it to achievement". Artinya, otonomi didefinisikan sebagai tindakan dan keputusan independen yang diambil oleh individu atau tim untuk mencapai tujuan organisasi, dan membawanya hingga mencapai prestasi.

Menurut Lumpkin \& Dess (1996: 141) Otonomi adalah "autonomy is the ability to make decisions and then take action on those decisions independently, without the limitations of the organization".Artinya, otonomi adalah kemampuan untuk membuat keputusan dan kemudian melakukan tindakan atas keputusan tersebut secara independen, tanpa batasan dari organisasi.

Kinerja Usaha. Menurut Mangkunegara (2001; dalam Koesmono, 2005: 28) Kinerja usaha adalah hasil kerja yang secara kualitas dan kuantitas dapat dicapai oleh seorang pegawai dalam melaksanakan tugas sesuai dengan tanggung jawab yang diberikan kepadanya

Menurut Soeprihantono (1988: 7) Mendeskripsikan bahwa kinerja adalah hasil pekerjaan seorang karyawan selama periode tertentu dibandingkan dengan berbagai kemungkinan, misalnya standard, target/sasaran/kriteria yang telah ditentukan terlebih dahulu dan telah disepakati bersama

Menurut Cascio (1995: 275) Kinerja adalah "Performance is the achievement of the tasks that have been determined". Artinya, kinerja adalah pencapaian tugas yang telah ditentukan.

Kaitan antara Kreativitas dan Kinerja Usaha. Kreativitas dalam anggota organisasi baik dalam pembuatan produk, gagasan atau ide dapat mempermudah saat bekerja dan meningkatkan kinerja. Menurut Barney \& Grant (1991; dalam Syed Zulfiqar Ali Shah \& Maqsood Ahmad, 2019) Kemampuan kreatif dan inovatif yang berharga dari seorang wirausahawan dapat memfasilitasi kinerja perusahaan. Eddy Poernomo (2006) berpendapat bahwa kreativitas dapat meningkatkan kinerja perusahaan, dalam proses mencapai profitabilitas yang dinginkan perlu ada kreativitas dari setiap anggota organisasi, adanya kreativitas dalam membuat sesuatu baik barang atau jasa dan gagasan akan mempermudah cara kita bekerja yang diharapkan dapat meraih keuntungan bagi perusahaan. Kemudian 
Kurnianingsih (2001; dalam Sunaryo, H., \& ABS, M. K., 2017) menyatakan bahwa untuk dapat meningkatkan kinerja perusahaan dalam mencapai profitabilitas dibutuhkan kreativitas dari setiap anggota perusahaan.

\section{H1: Terdapat hubungan yang signifikan antara kreativitas terhadap kinerja usaha.}

Kaitan antara Proaktif dan Kinerja Usaha. Sikap proaktif dalam organisasi baik dalam menciptakan peluang baru dan inovasi dapat meningkatkan kinerja perusahaan, karena dapat memimpin pasar terlebih dahulu dan meningkatkan profitabilitas usaha. Menurut Crant (1995; dalam Achmad Nurofi, 2014) menyatakan bahwa kinerja akan muncul karena karyawan lebih proaktif dalam menciptakan situasi yang akan memberikan kontribusi untuk kinerja yang lebih baik. Elia Quantananda dan Bambang Haryadi (2015) berpendapat bahwa proaktif merupakan dimensi yang berperan dalam kinerja bisnis, tidak hanya bagi perusahaan yang baru berjalan tapi juga perusahaan yang telah mengalami tahap pertumbuhan. Selanjutnya, I Made Sukaryawan (2013) dengan menciptakan peluang baru, selalu berinovasi, dan proaktif dalam melihat peluang pasar yang ada dapat mendorong peningkatan kinerja.

\section{H2: Terdapat hubungan yang signifikan antara proaktif terhadap kinerja usaha.}

Kaitan antara Otonomi dan Kinerja Usaha. Sikap otonomi dalam organisasi dapat meningkatkan kinerja karena seseorang memiliki kebebasan untuk mengungkapkan pemikiran, gagasan dan mengambil keputusan dalam memberikan ide guna meningkatkan bisnis. Menurut Siagian (1997; dalam Anik Irawati, 2008) Otonomi kerja merupakan rasa tanggung jawab atas pekerjaan seseorang beserta hasil dari pekerjaanya. Reskino (2016; dalam Harwita dan Ade Irma Suryani, 2018) berpendapat bahwa otonomi merupakan independensi, tingkat kebebasan, dan kebijaksanaan yang dimiliki seseorang dalam merencanakan suatu pekerjaan dan menentukan cara apa yang digunakan untuk melaksanakanya agar mencapai hasil yang diinginkan. Berikutnya, Kalbers dan Cenker (2008; dalam Pratiwi, S., \& Reskino, R., 2016) telah membuktikan bahwa dengan mempunyai otonomi maka kinerja akan semakin tinggi juga.

\section{H3: Terdapat hubungan yang signifikan antara otonomi terhadap kinerja usaha.}

Berdasarkan uraian kaitan antar variabel di atas, maka model penelitian yang digunakan dalam penelitian ini adalah sebagai berikut:

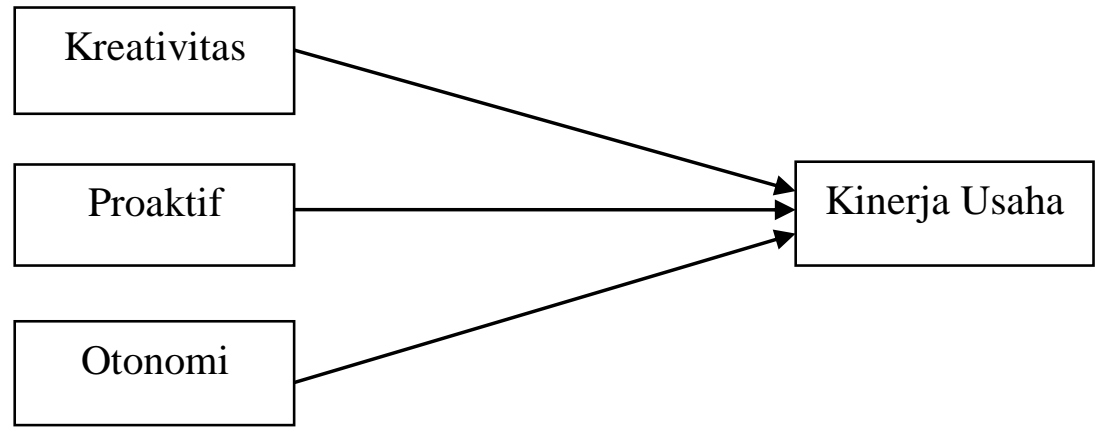

Gambar 1. Model Penelitian

\section{METODOLOGI}

Dalam penelitian ini peneliti menggunakan desain penelitian kuantitatif dan deskriptif. Penelitian deskriptif ini di desain untuk mendeskripsikan suatu peristiwa, kejadian dan gejala yang terjadi saat ini. Penelitian ini menggunakan metode survei yaitu penelitian yang 
mengambil sampel dari suatu populasi dan menggunakan kuesioner sebagai alat untuk mengumpulkan data dalam menganalisis penelitian (Singarimbun, 2006).

Populasi dalam penelitian ini adalah seluruh pemilik usaha makanan dan minuman. Dalam penelitian ini, peneliti menggunakan teknik judgemental sampling yang bertujuan untuk mempermudah proses pengumpulan data. Metode pengambilan sampel yang digunakan pada penelitian ini adalah non-probability sampling. Menurut Sugiyono (2001) nonprobability sampling adalah teknik pengambilan sampel dimana tidak semua anggota populasi dapat menjadi sampel. Oleh sebab itu, sampel yang digunakan dalam penelitian ini adalah sebanyak 41 orang pemilik usaha makanan dan minuman di Jakarta Barat.

Pengukuran variabel-variabel dalam penelitian ini mengacu pada penelitian sebelumnya antara lain sebagai berikut:

Tabel 1. Acuan penelitian

\begin{tabular}{|c|c|c|}
\hline Variabel & Indikator & Acuan \\
\hline Kreativitas & 7 & Abdullah Al Mamun dan Syed Ali Fazal (2018) \\
\hline Proaktif & 6 & Abdullah Al Mamun dan Syed Ali Fazal (2018) \\
\hline Otonomi & 5 & Abdullah Al Mamun dan Syed Ali Fazal (2018) \\
\hline Kinerja Usaha & 5 & Abdullah Al Mamun dan Syed Ali Fazal (2018) \\
\hline
\end{tabular}

\section{HASIL UJI STATISTIK}

Analisis validitas, baik convergent validity maupun discriminant validity, telah dilakukan dengan menggunakan analisis loading factors, dan cross loadings. Hasil analisis validitas menunjukan bahwa setiap variabel dan indikator dalam penelitian ini valid untuk digunakan. Kelima variabel yang digunakan dalam penelitian ini juga dinyatakan reliable. Sebab, Convergent Validity dianggap terpenuhi jika setiap indikator pada factor loading mempunyai nilai $\geq 0.5$ karena nilai tersebut merupakan nilai yang memadai (Ghozali., 2008; Hair et al., 2010). Selain itu, dalam menganalisis reliabilitas penelitian ini menggunakan 2 metode yaitu cronbach alpha dan composite reliability dengan kriteria nilai adalah $\geq 0.6$ (Malhotra., 2010).

Pengujian $\left(R^{2}\right)$ bertujuan untuk mengetahui kemampuan variabel independen yaitu kreativitas, proaktif dan otonomi dalam menjelaskan variabel dependen yaitu kinerja usaha. Hasil uji r-square dalam penelitian ini menunjukan bahwa sebesar 0.774 atau sebesar 77,4\% dari variabel dependen yaitu kinerja usaha dapat dijelaskan oleh variable kreativitas, proaktif dan otonomi yang diteliti pada penelitian ini, sisanya sebesar $22.6 \%$ dapat dijelaskan oleh variabel-variabel lain yang tidak diteliti dalam penelitian ini. Selanjutnya, Pengujian predictive relevance $\left(Q^{2}\right)$ bertujuan untuk mengetahui hubungan konstruk dari setiap variabel yang diteliti pada penelitian ini dalam mengukur model penelitian yang telah terbentuk sebelumnya. Hasil dari pengujian predictive relevance dalam penelitian ini menunjukan bahwa hubungan konstruk variabel-variabel yang diteliti dalam penelitian ini dianggap relevan untuk mengukur model penelitian yang telah terbentuk sebelumnya dengan baik. Hal ini dapat diketahui dari pengujian predictive relevance $\left(\mathrm{Q}^{2}\right)$ dalam penelitian ini sebesar 0,374 untuk variabel kinerja usaha yang artinya nilai predictive relevance $\left(Q^{2}\right)$ dalam penelitian ini lebih besar dari pada 0 .

Pengujian effect size $\left(f^{2}\right)$ bertujuan untuk mengetahui hasil dan pengaruh suatu variabel dalam model penelitian dengan kondisi ada atau dieliminasinya suatu variabel tertentu. Hasil pengujian effect size dalam penelitian ini menunjukan bahwa variabel kreativitas memiliki 
efek perubahan yang sedang terhadap kinerja usaha yaitu dengan nilai sebesar 0,206. Berikutnya, variabel proaktif memiliki efek perubahan yang besar terhadap kinerja usaha yaitu dengan nilai sebesar 0,453. Selanjutnya, variabel otonomi memiliki efek perubahan yang besar terhadap kinerja usaha yaitu dengan nilai sebesar 0.427. Selain itu, dilakukan pengujian goodness of fit (GoF) untuk menggambarkan seberapa besar nilai variabel dependen dapat memprediksi keseluruhan model. Hasil pengujian penelitian ini menunjukan bahwa model yang digunakan pada penelitian ini memiliki (Goodness of Fit) atau kecocokan yang termaksud besar yaitu 0.6356 .

Pengujian path coefficient bertujuan untuk mengetahui hubungan antar variabel yang terdapat pada penelitian ini. Suatu hipotesis dapat dikatakan signifikan apabila nilai tstatistics lebih besar dari 1,966 dan p-values kurang dari 0,05. Berikut ini merupakan hasil pengujian hipotesis:

Tabel 2. Hasil Pengujian Hipotesis

\begin{tabular}{|c|c|c|c|c|c|}
\hline & Hipotesis & Original sampel & T-statistik & P-value & Kesimpulan \\
\hline H1 & Kreativitas $\rightarrow$ kinerja usaha & 0.305 & 3.098 & 0.002 & Signifikan \\
\hline H2 & Proaktif $\rightarrow$ kinerja usaha & 0.402 & 4.290 & 0.000 & Signifikan \\
\hline H3 & Otonomi $\rightarrow$ kinerja usaha & 0.374 & 4.681 & 0.000 & Signifikan \\
\hline
\end{tabular}

Hasil pengujian hipotesis yang diperoleh mengenai pengaruh kreativitas terhadap kinerja usaha dalam penelitian ini mendapatkan nilai t-statistik sebesar 3.098 yang lebih besar dari batas minimum yaitu 1.96. Selain itu, nilai p-value juga sebesar 0.002 yang lebih kecil dari batas minimumnya yaitu $\alpha=0,05$. Ini berarti H1 tidak ditolak, maka dapat disimpulkan bahwa terdapat hubungan yang signifikan antara kreativitas terhadap kinerja usaha.

Berikutnya, hasil pengujian hipotesis yang diperoleh mengenai pengaruh proaktif terhadap kinerja usaha dalam penelitian ini mendapatkan nilai t-statistik sebesar 4.290 yang lebih besar dari batas minimum yaitu 1.96. Selain itu, nilai p-value juga sebesar 0.000 yang lebih kecil dari batas minimumnya yaitu $\alpha=0,05$. Ini berarti $\mathrm{H} 2$ tidak ditolak, maka dapat disimpulkan bahwa terdapat hubungan yang signifikan antara proaktif terhadap kinerja usaha.

Terakhir hasil pengujian hipotesis yang diperoleh mengenai pengaruh otonomi terhadap kinerja usaha dalam penelitian ini mendapatkan nilai t-statistik sebesar 4.681 yang lebih besar dari batas minimum yaitu 1.96. Selain itu, nilai p-value juga sebesar 0.000 yang lebih kecil dari batas minimumnya yaitu $\alpha=0,05$. Ini berarti $\mathrm{H} 3$ tidak ditolak, maka dapat disimpulkan bahwa terdapat hubungan yang signifikan antara otonomi terhadap kinerja usaha.

\section{DISKUSI}

Hasil dari analisis ini menunjukan bahwa $\mathrm{H} 1$ tidak ditolak, yang artinya terdapat hubungan yang signifikan antara kreativitas terhadap kinerja usaha makanan dan minuman di Jakarta Barat. Hipotesis ini juga didukung oleh Barney \& Grant (1991; dalam Syed Zulfiqar Ali Shah \& Maqsood Ahmad,2019) yang menyatakan bahwa kemampuan kreatif dan inovatif yang berharga dari seorang wirausahawan dapat memfasilitasi kinerja perusahaan. Selanjutnya, Hasil analisis penelitian ini juga menunjukan bahwa $\mathrm{H} 2$ tidak ditolak, yang artinya terdapat hubungan yang signifikan antara proaktif terhadap kinerja usaha makanan dan minuman di Jakarta Barat. Hipotesis ini juga didukung oleh Elia Quantananda dan Bambang Haryadi (2015) yang menyatakan bahwa proaktif merupakan dimensi yang berperan dalam kinerja bisnis, tidak hanya bagi perusahaan yang baru berjalan tapi juga 
perusahaan yang telah mengalami tahap pertumbuhan. Berikutnya, pengujian hipotesis terakhir dalam penelitian ini juga menunjukan bahwa $\mathrm{H} 3$ tidak ditolak, yang artinya terdapat hubungan yang signifikan antara otonomi terhadap kinerja usaha makanan dan minuman di Jakarta Barat. Hipotesis ini juga didukung oleh Reskino (2016; dalam Harwita dan Ade Irma Suryani,2018) yang menyakatakan bahwa otonomi merupakan independensi, tingkat kebebasan, dan kebijaksanaan yang dimiliki seseorang dalam merencanakan suatu pekerjaan dan menentukan cara apa yang digunakan untuk melaksanakanya agar mencapai hasil yang diinginkan.

\section{PENUTUP}

Berdasarkan hasil analisis dan pembahasan pada bab sebelumnya, dapat disimpulkan bahwa pertama, kreativitas memiliki memiliki pengaruh terhadap kinerja usaha makanan dan minuman di Jakarta Barat. Kedua, Proaktif memiliki memiliki pengaruh terhadap kinerja usaha makanan dan minuman di Jakarta Barat. Terakhir, Otonomi memiliki memiliki pengaruh terhadap kinerja usaha makanan dan minuman di Jakarta Barat.

Peneliti menyarankan pemilik usaha makanan dan minuman agar memperluas pengetahuannya dalam kreativitas yaitu gagasan yang berbeda dalam membuat produk. Selanjutnya, proaktif yang merupakan kemampuan mencari peluang di masa mendatang. Dan otonomi yaitu kemampuan dalam mengambil keputusan secara independen. Karena berdasarkan penelitian ini kreativitas, proaktif dan otonomi sangat penting dalam meningkatkan kinerja usaha. Selanjutnya, untuk penelitian mendatang peneliti menyarankan agar memperbanyak jumlah sampel agar dapat memperkuat hasil penelitian. Terakhir untuk penelitian mendatang peneliti menyarankan untuk menambah dan mengembangkan variabelvariabel lain seperti pengambilan resiko, inovatif dan agresifitas.

\section{DAFTAR PUSTAKA}

Aloulou, W., \& Fayolle, A. (2005). A conceptual approach of entrepreneurial orientation within small business context. Journal of Enterprising Culture, 13(01), 21-45.

Brahmasari Ida Ayu, (2004). Pengaruh Variabel Budaya Perusahaan terhadap Komitmen Karyawan dan Kinerja Perusahaan Kelompok Penerbitan Pers Jawa Pos, Disertasi Universitas Airlangga, Surabaya.

Cascio, Wayne F, (1995),Managing Human Resources: Productivity, Quality of worklife, Profits. Fourth Edition. Singapore : McGraw Hill Inc.

Crant, J. M. (2000). The proactive personality scale in organizations. Journal of Management, $80,435-462$.

Dess, Gregory G., \& G. Tom Lumpkin. "The role of entrepreneurial orientation in stimulating effective corporate entrepreneurship." Academy of Management Perspectives 19.1 (2005): 147-156.

Eddy Poernomo (2016). "Pengaruh Kreativitas dan Kerjasama Tim Terhadap Kinerja Manajer PT.Jesslyn K Cakes Indonesia” Jurnal Ilmu-Ilmu Ekonomi Vol.6 No.2 , pp.102-108

Elia Quantananda, \& Bambang Haryadi. (2015). "Pengaruh Orientasi Kewirausahaan Pada Perusahaan Makanan dan Minuman di Surabaya." AGORA Vol. 3, No. 1

Hair Jr, J.F., Black, W.C., Babin, B.J., \& Anderson, R.E. (2010). Multivariate Data Analysis $7^{\text {th }}$ Edition, Prentice-Hall International, Inc.

Harwita, A. I. S. (2018). Pengaruh Otonomi Terhadap Kinerja Pegawai Dengan Kejelasan Tujuan Organisasi Sebagai Pemediasi Pada PT.PLN (PERSERO) Wilayah Aceh. Jurnal Ilmiah Mahasiswa Ekonomi Manajemen, 3(3), 59-72. 
Irawati, A. (2008). Pengaruh Kepuasan Kerja Dan Otonomi Kerja Terhadap Kinerja Karyawan Bagian Pemasaran PT. Paloma Citra Internasional Surakarta (Doctoral dissertation, Universitas Muhammadiyah Surakarta).

I Made Sukaryawan. (2013).’Pengaruh Orientasi Pasar, Kewirausahaan, dan Inovasi Terhadap Kinerja Bisnis pada Perusahaan Aspal-Beton (Hotmix) di JABODETABEK.’Jurnal MIX, Volume III, No. 2

Johannessen, J.-A., Olaisen, J. \& Olsen, B. (1999) "Managing and organizing innovation in the knowledge economy “, European Journal of Innovation Management, Vol. 2, No. 3, pp.116-128

Koesmono H. Teman, (2005). Pengaruh Budaya Organisasi terhadap Motivasi dan Kepuasan Kerja serta Kinerja Karyawan pada Sub Sektor Industri Pengolahan Kayu Ekspor di Jawa Timur, Disertasi Universitas Airlangga, Surabaya.

Lambing, Peggy A \& Kuehl, Charles R. (2007). Entrepreneurship. New Jersey: Fourth Edition, Pearson Education

Lumpkin, G. T. \& Dess, G. G. (1996) "Clarifying the Entrpreneurial Orientation Construct and linking it to performance", Academy of Management Review, Vol. 21, pp. 141.

Lumpkin, G.T. \& Dess, G.G., (2001). Linking two dimensions of entrepreneurial orientation to firm performance: The moderating role of environment and industry life cycle. Journal of business venturing, 16(5), pp.429-451.

Malhotra, K. N. (2010). Marketing Research: An Applied Orientation, $6^{\text {th }}$ Edition. United States: Pearson.

Munandar, S.C. Utami. (2012). Pengembangan Kreativitas Anak Berbakat. RinekaCipta. Jakarta

Nurofi, A. (2014). Meningkatkan perilaku proaktif karyawan melalui peran pimpinan dan sistem kontrol. Jurnal Ilmu Manajemen dan Akuntansi Terapan, 5(1), 84-91.

Pratiwi, S., \& Reskino, R. (2016). Pengaruh Budaya Organisasi, Pelaksanaan Tanggung Jawab, Otonomi Kerja, dan Ambiguitas Peran Terhadap Kinerja Auditor (Studi Pada Kantor Akuntan Publik di Jakarta). Akuntabilitas, 9(1).

Shah, Syed Zulfiqar Ali, \& Maqsood Ahmad. "Entrepreneurial orientation and performance of small and medium-sized enterprises." Competitiveness Review: An International Business Journal (2019).

Singarimbun, Masri. "Effendi. (2006)." Metode Penelitian Survai.

Soeprihantono, J., (1988), Penilaian Pelaksanaan Pekerjaan dan Pengembangan Karyawan. Yogyakarta : BPFE-Yogyakarta.

Sugiyono (2001). Statistika untuk Penelitian, Bandung: Alfabeta.

Suharyadi (2007). Membangun usaha sukses sejak muda, Jakarta: Salemba Empat

Sulistyastuti, D.R., (2004). Dinamika Usaha Kecil dan Menengah (UKM) Analisis Konsentrasi Regional UKM di Indonesia 1999 â€"2001. Economic Journal of Emerging Markets, 9(2).

Sunaryo, H., \& ABS, M. K. (2017). Pengaruh Kerjasama Tim dan Kreativitas Terhadap Kinerja Karyawan UD. AGRO INTI SEJAHTERA JEMBER. Jurnal Ilmiah Riset Manajemen, 6(04).

Wright, Paul H. (2005). Introduction to engineering. Edisi 3, Jakarta:Erlangga

Yuliati, N. A.(2007). "Peningkatan kreativitas Seni Dalam desain Budaya". Jurnal Seni dan Pendidikan, Vol.5, No.2, pp.173-184

https://www.pikiran-rakyat.com/ekonomi/pr-01316389/pertumbuhan-industri-makanan-danminuman-sumbang-635-terhadap-pdb-nasional 